\title{
Sistem Pakar Diagnosa Penyakit Tanaman Bawang Merah Menggunakan Metode Certainty Factor
}

\author{
Mohammad Fathor Rosi' ${ }^{1}$ Bakhtiyar Hadi Prakoso \\ ${ }^{1}$ Jurusan Teknik Informatika, Universitas Muhammadiyah Jember, mfatho@email.com \\ ${ }^{2}$ Jurusan Kesehatan, Politeknik Negeri Jember, bakhtiyar.hp@polije.ac.id
}

\begin{tabular}{l} 
Keywords: \\
\hline Expert System \\
Certainty Factor \\
Third Keyword
\end{tabular}

\section{Kata Kunci}

Sistem pakar

Certainty Factor

Red Onion

\begin{abstract}
The lack of knowledge of farmers and the unequal counseling about onion disease from experts is a strong reason for the difficulty of overcoming or immediately treated diseases of onions, for this requires early diagnosis of disease onion plants. This research uses the Certainty Factor method. This method uses the certainty of an expert on the symptoms of each disease. By determining the value of MB (Measure of Believe) as the level of confidence in the hypothesis and MD (Measure of Disbelieve) the level of distrust of the hypothesis. After using the Certainty Factor formula, the value of each disease will be generated from the new symptoms owned by using the highest value of each disease, so that is the result of disease diagnosis in shallots. This study uses as many as 35 data as testing and from these data obtained an accuracy value of $85.71 \%$
\end{abstract}

\begin{abstract}
ABSTRAK
Kurangnya pengetahuan petani dan belum meratanya penyuluhan tentang penyakit bawang merah dari pakar menjadi alasan kuat sulitnya mengatasi atau segera ditangani penyakit pada bawang merah, untuk itu diperlukan pendiagnosisan awal terhadap penyakit tanaman bawang merah. Penelitian ini menggunakan metode metode Certainty Factor. Metode ini menggunakan kepastian dari seorang pakar terhadap gejala-gejala setiap penyakit. Dengan menentukan nilai $\mathrm{MB}$ (Measure of Believe) sebagai tingkat kepercayaan terhadap hipotesa dan MD (Measure of Disbelieve) tingkat ketidak kepercayaan terhadap hipotesa. Setelah menggunakan rumus Certainty Factor maka akan dihasilkan nilai pada setiap penyakit dari gejala baru yang dimiliki dengan menggunakan nilai tertinggi dari setiap penyakit maka itulah hasil diagnosa penyakit pada tanaman bawang merah. Penelitian ini menggunakan sebanyak 35 data sebagai pengujianya dan dari data tersebut diperoleh nilai akurasi sebesar $85,71 \%$
\end{abstract}

\author{
Korespondensi Penulis: \\ Bakhtiyar Hadi Prakoso, \\ Politeknik Negeri Jember, \\ Jl. Mastrip No 164 Jember \\ Telepon : +62 82257197272 \\ Email: bakhtiyar.hp@polije.ac.id
}

\section{PENDAHULUAN}

Bawang merah (Allium ascalonicum Linn.) merupakan salah satu komoditas sayuran yang potensial untuk dikembangkan di Indonesia. Bawang merah termasuk sayuran yang multiguna yang dimanfaatkan sebagai rempahrempah pelengkap bumbu masak, bahan untuk industri makanan dan dipakai sebagai obat tradisional (Putrasamedja, 1996). Beberapa kendala produksi bawang merah diantaranya masih tingginya intensitas serangan penyakit, ketersediaan benih bermutu belum mencukupi secara tepat, belum tersedia varietas unggul yang tahan terhadap penyakit utama, penerapan teknik budidaya yang baik belum dilakukan secara optimal, kelembagaan petani belum dapat menjadi pendukung usaha tani, skala usaha relatif masih kecil akibat sempitnya kepemilikan lahan dan lemahnya permodalan [1]. Para petani bawang merah mengeluhkan bahwa banyaknya penyakit yang menyerang bawang merah menjadi penyebab menurunnya penghasilan bawang merah. Kurangnya pengetahuan petani dan belum meratanya 
penyuluhan tentang penyakit bawang merah dari pakar menjadi alasan kuat sulitnya mengatasi atau segera ditangani penyakit pada bawang merah, untuk itu diperlukan pendiagnosisan awal terhadap penyakit tanaman bawang merah.

Certainty Factor adalah ukuran kepastian terhadap suatu fakta atau aturan [2]. Certainty Factor memberikan suatu konsep Measure of Believe (MB) adalah keyakinan hipotesis yang dipengaruhi oleh gejala dan Measure of Disbelieve (MD) adalah ketidakyakinan hipotesa yang dipengaruhi oleh gejala. Metode ini mengukur pasti atau tidak pasti dalam mendiagnosa penyakit sebagai salah satu contohnya. Banyak sekali implementasi dari Certainty Factor dalam sistem pendukung keputusan, diantaranya adalah sistem pendukung keputusan untuk mendiagnosa penyakit osteporosis [3]. Selain itu dalam bidang kesehatan, juga untuk mendiagnosa penyakit THT [4]. Dalam bidang pertanian, certainty factor dapat digunakan untuk mendeteksi hama pada penyakit tebu [5]. Pada penelitian yang dilakukan oleh Alfan certainty factor digunakan untuk mendiagnosa penyakit pada tanaman apel [6]. Dari beberapa penelitian yang telah dilakukan certainty factor dapat digunakan untuk membantu dalam pengambilan keputusan. Kelebihan dari metode CF adalah dapat mengukur sesuatu yang pasti atau tidak pasti dalam pengambilan keputusan pada sistem pakar diagnosa penyakit Dengan dasar tersebut, pada penelitian ini mencoba membahas implementasi metode certainty factor dalam membantu mendiagnosa penyakit pada tanaman bawang merah.

\section{METODE PENELITIAN}

Untuk menyelesaikan penelitian ini terdapat tahapan atau langkah yang harus diselesaikan. Adapun langkahlangkah penyelesaian ini dapat dijelaskan pada gambar 1:

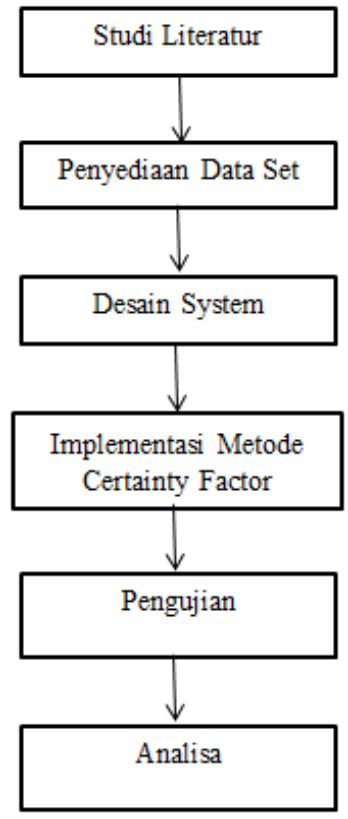

Gambar 1. Blok Diagram Tahapan Penelitan

Pengumpulan data dengan cara mengumpulkan bahan-bahan referensi jurnal,paper,buku dan wawancara kepada narasumber yang terkait dengan judul penelitian, guna melengkapi pengetahuan dasar, mempelajari dan memahami teory tentang Certainty Factor. Data didapatkan melalui para petani bawang merah yang di Kabupaten Bondowoso. Langkah selanjutnya yaitu membangun desain sistem dan mengimplementasikan metode Certainty Factor dengan menentukan nilai MB dan MD dari tiap gejala. Lalu dilanjutkan dengan menghitung nilai CF. Untuk menilai apakah sistem yang telah dibuat telah akurat atau sebalikannya dilakukan dengan mengukur tingkat akurasi. Langkah yang terakhir berupa analisa, pada langkah ini akan dilakukan penarikan kesimpulan dari penelitian yang dilakukan

\subsection{Penyediaan Data}

Data penyakit tanaman bawang merah yang dibuat sebagai acuan adalah data yang didapatkan dari pengambilan petani di daerah kemuning-Bondowoso. Selain data yang berasal dari para petani data juga didapatkan dari pakar. Referensi pakar didapatkan dari hasil wawancara dengan dosen pakar fakultas pertanian. Dari hasil wawancara dengan pakar didapakatkan data penyakit dan gejalannya. Adapun gejala dan penyakit bawang merah dapat dijelaskan pada tabel 1 . 
Tabel 1 Relasi penyakit dan gejala

\begin{tabular}{|c|c|c|c|c|c|c|c|c|}
\hline \multirow[b]{2}{*}{ Kode } & \multirow[b]{2}{*}{ GEJALA } & \multicolumn{7}{|c|}{ PENYAKIT } \\
\hline & & $\begin{array}{c}\text { P1 } \\
\text { Bercak } \\
\text { ungu }\end{array}$ & $\begin{array}{c}\text { P2 } \\
\text { Embun } \\
\text { buluk }\end{array}$ & $\begin{array}{c}\text { P3 } \\
\text { Antra } \\
\text { knosa }\end{array}$ & $\begin{array}{c}\text { P4 } \\
\text { Mati } \\
\text { pucuk }\end{array}$ & $\begin{array}{c}\text { P5 } \\
\text { Ngelu } \\
\text { mpruk }\end{array}$ & $\begin{array}{c}\text { P6 } \\
\text { Moler }\end{array}$ & $\begin{array}{c}\text { P7 } \\
\text { Bercak } \\
\text { daun }\end{array}$ \\
\hline G1 & Binti-bintik putih & $\sqrt{ }$ & & & & & & $\sqrt{ }$ \\
\hline G2 & $\begin{array}{l}\text { Bercak daun } \\
\text { berwarna putih } \\
\text { atau kelabu }\end{array}$ & $\sqrt{ }$ & $\sqrt{ }$ & & & & & \\
\hline G3 & $\begin{array}{l}\text { Bercak daun } \\
\text { berwarna ungu }\end{array}$ & $\sqrt{ }$ & $\sqrt{ }$ & & & & & \\
\hline G4 & Bercak hijau & $\sqrt{ }$ & $\sqrt{ }$ & $\sqrt{ }$ & & & & \\
\hline G5 & $\begin{array}{l}\text { Bercak merah } \\
\text { keunguan }\end{array}$ & $\sqrt{ }$ & $\sqrt{ }$ & & & & & \\
\hline G6 & $\begin{array}{l}\text { Bercak daun } \\
\text { berwarna choklat }\end{array}$ & & & $\sqrt{ }$ & & & & $\sqrt{ }$ \\
\hline G7 & $\begin{array}{l}\text { Bercak daun } \\
\text { berwarna putih }\end{array}$ & $\sqrt{ }$ & & $\sqrt{ }$ & & $\sqrt{ }$ & & \\
\hline G8 & $\begin{array}{l}\text { Bercak daun putih } \\
\text { kekuningan }\end{array}$ & & & $\sqrt{ }$ & & $\sqrt{ }$ & & $\sqrt{ }$ \\
\hline G9 & Daun menguning & $\sqrt{ }$ & $\sqrt{ }$ & & & & $\sqrt{ }$ & \\
\hline G10 & Layu & & $\sqrt{ }$ & $\sqrt{ }$ & $\sqrt{ }$ & & $\sqrt{ }$ & \\
\hline G11 & $\begin{array}{l}\text { Daun } \\
\text { choklat/putih }\end{array}$ & & & $\sqrt{ }$ & $\sqrt{ }$ & & & \\
\hline G12 & $\begin{array}{l}\text { Daun belang } \\
\text { hijaun } \\
\text { pucat/kuning }\end{array}$ & & $\sqrt{ }$ & $\sqrt{ }$ & & & & $\sqrt{ }$ \\
\hline G13 & Daun kering & $\sqrt{ }$ & $\sqrt{ }$ & & $\sqrt{ }$ & & & \\
\hline
\end{tabular}

Pada tabel di atas, terdapat relasi antara gejala dan penyakit. Setiap penyakit memiliki gejala yang ditandai dengan tanda centang. Dikethaui penyakit yang akan menjadi bahan penelitian ini macem 7 penyakit, yaitu bercak ungu, embun bulu, antraknosa, mati pucu, moler, ngelumpruk, dan bercak daun. Sedang kan gejalanya terdapat sebanyak 13 gejala.

\subsection{Penentuan nilai $\mathrm{CF}$ gejala}

Tahap awal yang harus dilakukan adalah penentuan nilai CF gejala. Dimulai dengan menentukan nilai Probabilitas hipotesa penyakit yang dipengaruhi oleh gejala $\mathrm{P}(\mathrm{HIE})$ dengan menghitung tingkat kemunculan gejala dari setiap penyakit dengan kode P sedangkan gejala dengan kode G. Selanjutnya menentukan nilai Probabilitas, fungsinya untuk mengetahui besarnya nilai kemungkinan tiap gejala bisa dimiliki oleh berapa penyakit.yang ketiga adalah menentukan nilai $\mathrm{P}(\mathrm{H})$ tiap gejala, yaitu dengan cara masing-masing setiap nilai probabilitas gejala dibagijumlah gejala yaitu 15. Selanjutnya menghitung nilai MB (Measure of believe)dan MD (Measure of Disbelieve) dengan diperolehnya nilai $\mathrm{MB}$ dan $\mathrm{MD}$ maka sesuai dengan rumus $\mathrm{CF}=\mathrm{MB}-\mathrm{MD}$, maka akan diperoleh nilai $\mathrm{CF}$ tiap gejala sehingga jika dilakukan perhitungan diagnosa penyakit dihitunglah $\mathrm{CF}$ combine dari setiap nilai $\mathrm{CF}$ gejala. Maka setelah dilakukan perhitungan $C F$ Combine dari beberapa gejala pada tiap-tiap penyakit, nilai $C F$ combine yang tertinggilah yang menjadi penentuan penyakit tanaman bawang merah yang baru. Adapun rumus metode Certainty Factor sebagai berikut [7]:

$$
\begin{gathered}
C F[H, E]=M B[H, E]-M D[H, E] \\
M B(H / E)=\frac{\max [P(H \mid E), P(H)]-P(H)}{1-P(H \mid E)} \\
M D(H / E)=\frac{\min [P(H \mid E), P(H)]-P(H)}{-P(H)}
\end{gathered}
$$


Keterangan:

- CF : Certainty Factor (factor kepastian) dalam hipotesis H yang dipengaruhi oleh gejala (Evidence) E. Besarnya CF berkisar antara -1 sampai dengan 1. Nilai -1 mrnunjukkan ketidakpercayaan mutlak sedangkan nilai 1 menunjukkan kepercayaan mutlak.

- $\quad \mathbf{M B}[\mathbf{H}, \mathbf{E}]$ : ukuran kenaikan kepercayaan (measure of beliefe) terhadap hipotesis $\mathrm{H}$ yang di pengaruhi oleh gejala E.

- $\quad \mathbf{M D}[\mathbf{H}, \mathbf{E}]$ : ukuran kenaikan ketidakpercayaan (Measure of disbelief) terhadap Hipotesis H dipengaruhi oleh gejala E.

- $\quad \mathbf{P}(\mathbf{H I E})$ : probabilitas $\mathrm{H}$ hipotesa yang di perngaruhi oleh evidence E.

- $\quad \mathbf{E}:$ Evidence (peristiwa atau fakta).

- $\quad \mathbf{H}:$ Hipotesis (dugaan)

- [7] : probabilitas kebenaran hipotesis $\mathrm{H}$.

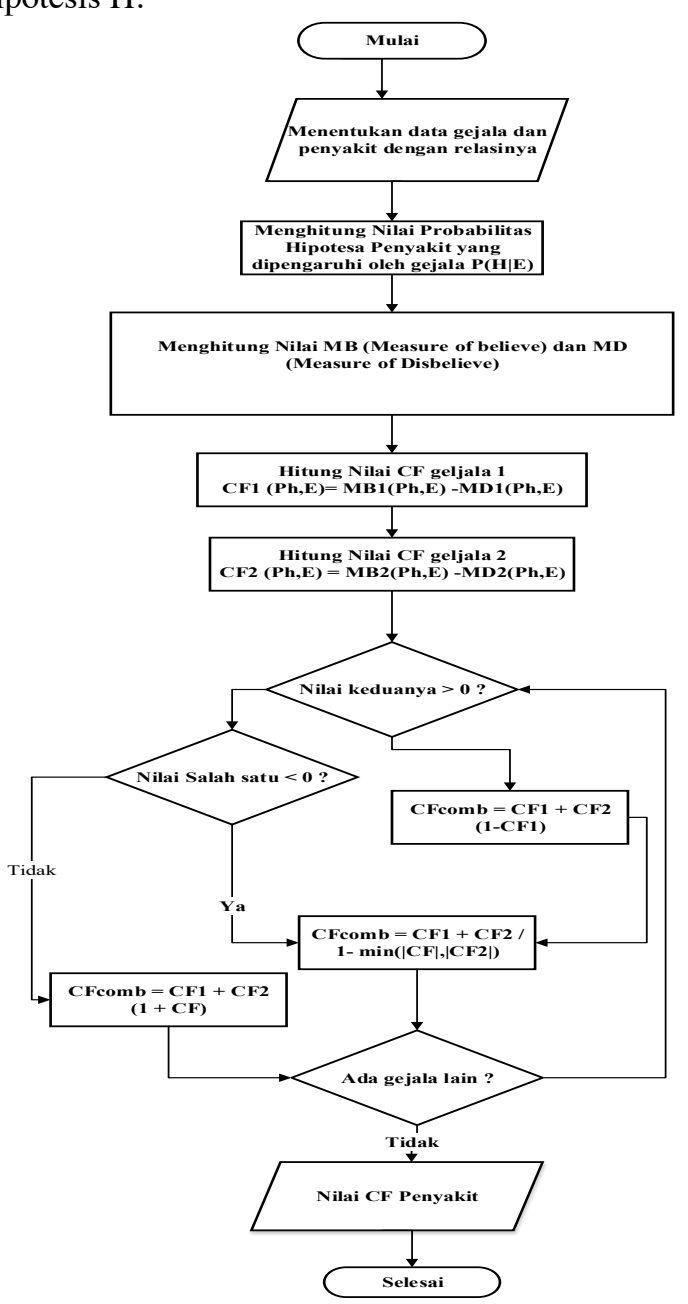

Gambar 2. Flowchart Perhitungan Metode Certainty Factor

Gambar 2 merupakan cara menentukan nilai CF penyakit pada tanaman bawang merah yang dilakukan beberapa tahap. Tahapan tersebut terdiri dari 7 proses dan adapula kondisi (seleksi) yang menentukan rumus yang akan dipakai pada perhitungan tersebut.

\section{HASIL DAN ANALISIS}

Sistem pakar yang dikembangkan harus diberikan pengetahuan dan penalaran dari pengetahuan yang diadopsi dari pakar. Hal tersebut bertujuan agar sistem pakar yang dibuat dapat memberikan kesimpulan seperti halnya pakar. Dalam penelitian ini pengetahuan yang ditanamkan di aplikasi adalah berupa pengetahuan tentang gejala dan penyakit bawang merah. 
Tampilan Sistem pakar mendiagnosa penyakit tanaman bawang merah dengan metode Certainty Factor dapat dilihat sebagai berikut :

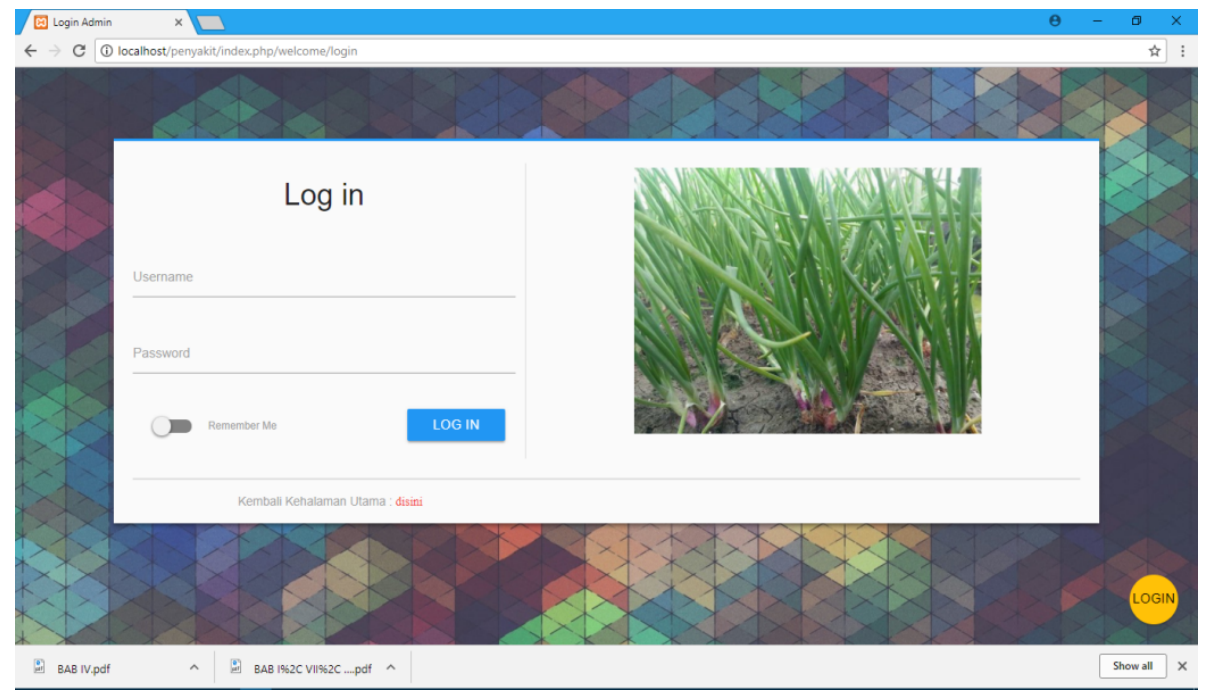

Gambar 3. Halaman awal sistem pakar

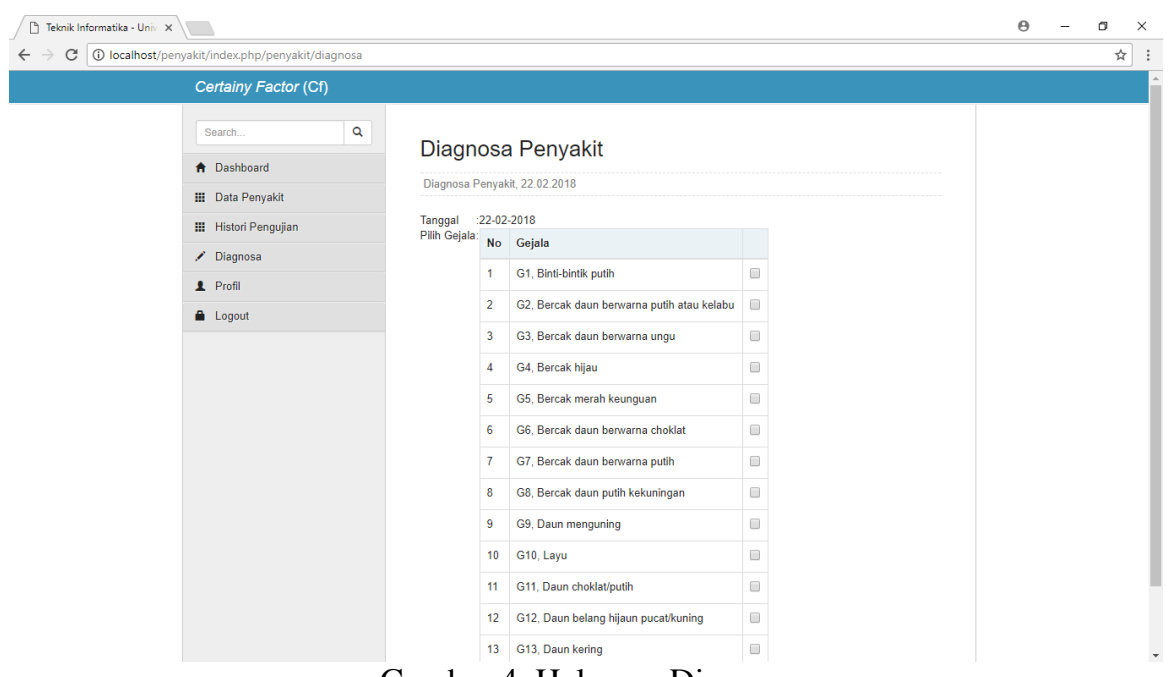

Gambar 4. Halaman Diagnosa.

Halaman Diagnosa merupakan halaman yang digunakan oleh user untuk melakukan diagnosa penyakit tanaman bawang merah yang sudah disediakan berdasarkan gejalanya dan menekan tombol Diagnosa setelah memilih dan mencentang. Diharapkan pengguna memilih dan teliti ketika menginputkan gejala yang di alaminya sehingga diagnosa yang diproses sistem akan mengidentifikasi diagnosa penyakitnya dengan benar. Pada Halaman hasil diagnosa berdasarkan gejala yang di alaminya. Halaman hasil diagnosa ini menampilkan tampilan secara rinci berupa nilai CF gejalanya pada tiap-tiap penyakit, karena gejala pada tiap-tiap penyakit berbeda. Perbedaan dari nilai CF tiap gejala dipengaruhi karena penyakit tersebut tidak memiliki gejala itu sendiri. 


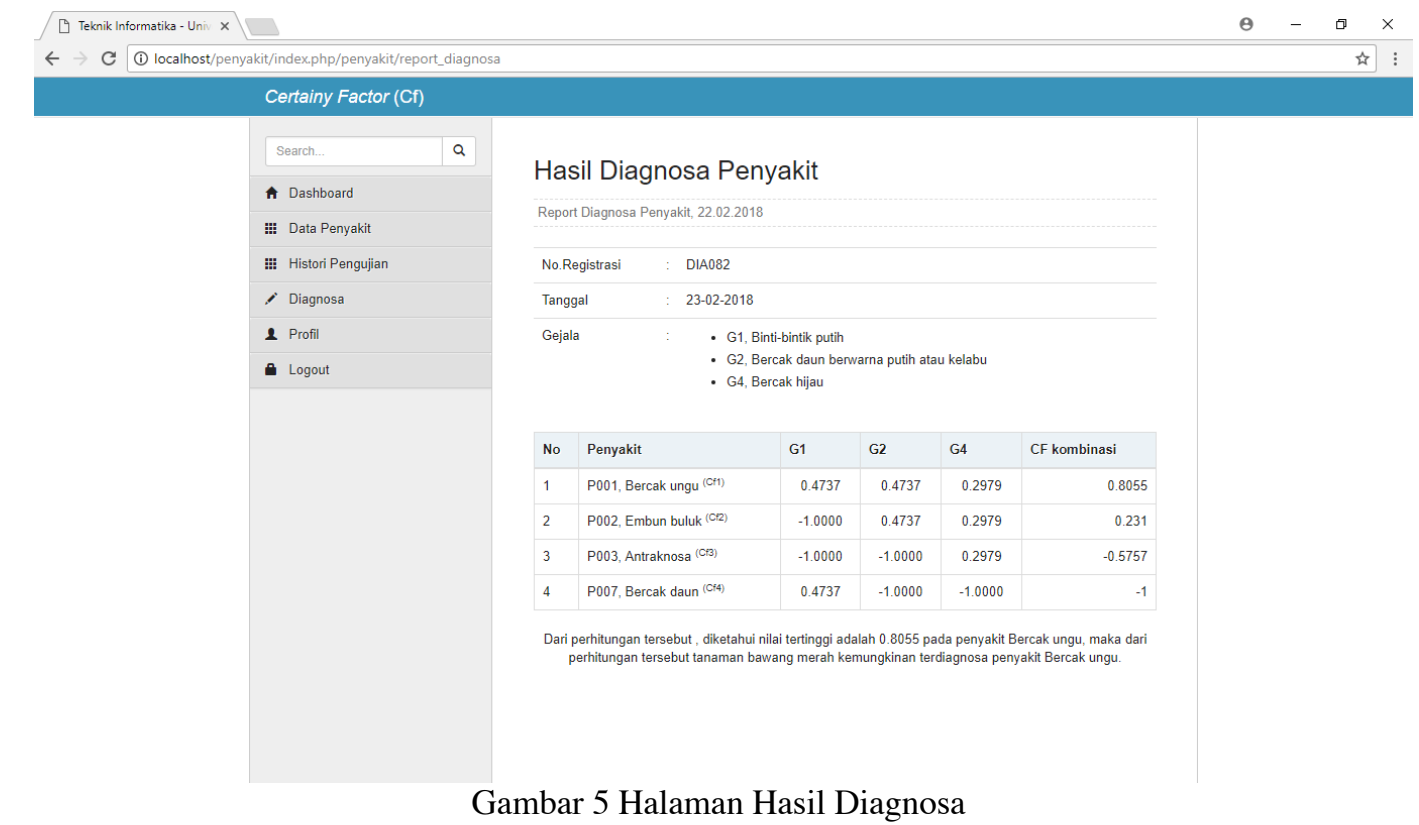

Pada Gambar 5 menunjukkan tanaman bawang merah terdiagnosa penyakit Bercak unggu. Berdasarkan konsep dari metode yang digunakan yaitu Certainty Factor, akan mendiagnosa penyakit berdasarkan hasil CF kombinasi yang tertinggi. Sehingga diperoleh hasil diagnosa pasien tersebut penyakit Bercak unggu.

Pengujian sistem dilakukan dengan melakukan evaluasi data yang sudah diketahui hasil diagnosisnya Pengujian ini menggunakan data yang di ambil dari petani bawang merah daerah Bondowoso, data es tes [1] berjumlah 35 data. Pengujian sistem berfungsi untuk mengetahui kinerja sistem sebagai tingkat akurasi pada sistem pakar diagnosa penyakit tanaman bawang merah. Berikut ini adalah keterangan gejalanya.

G1: $\quad$ Bintik-bintik putih

G2: $\quad$ Bercak daun berwarna putih atau kelabu

G3: Bercak daun berwarna unggu

G4: Bercak hijau

G5: Bercak merah keuunguan

G6: Bercak daun berwarna choklat

G7: Bercak daun berawaarna putih

G8: Bercak daun berwarna putih keunguan

G9: Daun menguning

G10: Layu

G11: Daun choklat atau putih

G12: Daun belang hijua pucat atau kuning

G13: Daun kering

Tabel 2. Hasil Perbandingan Diagnosa

\begin{tabular}{clllll}
\hline No. & $\begin{array}{c}\text { Nama } \\
\text { Petani }\end{array}$ & \multicolumn{1}{c}{ Timbul Gejala } & $\begin{array}{c}\text { Diagnosa } \\
\text { Pakar }\end{array}$ & Diagnosa Sistem & $\begin{array}{c}\text { Uji } \\
\text { tanimoto } \\
\text { distance }\end{array}$ \\
\hline 1 & P1 & G10 & Embun buluk & $\begin{array}{l}\text { Embunbuluk,antraknosa,mati } \\
\text { pucuk,moler }\end{array}$ & 0,75 \\
\hline 2 & P2 & G1, & Bercak unggu & Bercak unggu & 0 \\
\hline 3 & P3 & G1,G4,G5 & Bercak unggu & Bercak unggu & 0 \\
\hline 4 & P3 & G2,G5,G3 & Bercak unggu & Bercak unggu,embun bukuk & 1 \\
\hline 5 & P4 & G2,G10,G13 & Embun buluk & Embun bukuk & 0 \\
\hline 6 & P5 & G8,G9,G10 & Embun buluk & Embun buluk & 0 \\
\hline 7 & P6 & G8,G10,G13 & Embun buluk & Embun buluk & 0 \\
\hline 8 & P7 & G3,G4,G7 & Bercak unggu & Bercak unggu & 0 \\
\hline 10 & P8 & G6,G7 & Antraknosa & Antraknosa & 0 \\
\hline 11 & P9 & G6,G10 & Embun buluk & Embun buluk & 0 \\
\hline 12 & P10 & G6,G9 & Mati pucuk & Mati pucuk & 0 \\
\hline 13 & P11 & G11,G13, & Embun buluk & Embun buluk & 0 \\
\hline
\end{tabular}




\begin{tabular}{llllll}
\hline 14 & P12 & G5,G7 & Bercak unggu & Bercak unggu & 0 \\
\hline 15 & P13 & G1,G2,G3,G4,G5 & Bercak unggu & Bercak unggu & 0 \\
\hline 16 & P14 & G5,G6,G7,G8 & Antraknosa & Antraknosa & 0 \\
\hline 17 & P15 & G8,G9,G10,G11 & Mati pucuk & Mati pucuk & 0 \\
\hline 18 & P16 & G11,G12,G13 & Ngelumpruk & Ngelumpruk & 0 \\
\hline 19 & P17 & G8,G11,G13 & Moler & Moler & 0 \\
\hline 20 & P18 & G1,G4,G6 & Antraknosa & Antraknsa & 0 \\
\hline 21 & P19 & G1,G2,G4 & Bercak unggu & Bercak unggu & 0 \\
\hline 22 & P20 & G9,G11,G13 & Mati pucuk & Mati pucuk & 0 \\
\hline 23 & P21 & G10 & Embun buluk & Embun buluk & 0 \\
\hline 24 & P22 & G13 & Embun buluk & Embun buluk & 0 \\
\hline 25 & P23 & G6,G7,G8 & Antrknosa & Antraknosa & 0 \\
\hline 26 & P24 & G8,G12,G13 & Moler & Moler & 0 \\
\hline 27 & P25 & G3,G5 & Bercak unggu & Bercak unggu, embun buluk & 1 \\
\hline 28 & P26 & G9,G10,G11,G12,G12 & Ngelumpruk & Ngelumpruk & 0 \\
\hline 29 & P27 & G1,G9, & Bercak daun & Bercak daun & 0 \\
\hline 30 & P28 & G11,G1 & Bercak unggu & Bercak unggu & 0 \\
\hline 31 & P29 & G5,G10,G13 & Embun buluk & Embun buluk & 0 \\
\hline 32 & P30 & G1 & Bercak unggu & Bercak unggu,bercak daun & 1 \\
\hline 33 & P31 & G2 & Bercak unggu & Bercak unggu,embun buluk & 1 \\
\hline 34 & P32 & G2,G4,G5 & Embun buluk & Embun buluk & 0 \\
\hline 35 & P33 & G4,G10,G15 & Embun buluk & Embun buluk & 0 \\
\hline & & & & \\
\hline
\end{tabular}

Untuk menilai ketepatan antara diagnosa pakar pengujian menggunakan tanimoto distance yaitu semakin nilainya mendekati nol maka semakin banyak jumlah total kategori yang berhasil diprediksi secara benar. Diketahui hasil uji tanimoto distanceterdapat nilai 0, 0,75 dan 1. Artinya semakin nilai uji tanimoto semakin kecil artinya semakin mendekati benar. Pengujian tingkat akurasi yang dimaksud adalah untuk menemukan persentase ketepatan dalam proses pengklasifikasian terhadap data testing yang diuji. Tingkat akurasi dihitung dengan menggunakan rumus [8]:

$\Sigma$ match $=$ jumlah klasifikasi yang benar

$$
\text { Akurasi }=\frac{\Sigma \text { match }}{\Sigma \text { tp }} \times 100 \%
$$

$\Sigma \mathrm{TP}=$ jumlah data testing

Akurasi $=\frac{30}{35} \times 100 \%$

$=85,71 \%$

Dari hasil perhitungan uji akurasi diatas, menujukkan hasil akurasi sebesar $85,71 \%$ artinya system cukup baik untuk digunakan mendeteksi diagnose penyakitntanaman bawang merah.

\section{KESIMPULAN}

Berdasarkan pengukuran menggunakan metode Certainty Factor diketehui hasil combine tertinggi pada gejala tiap-tiap penyakit, dari hasil combine tertinngi yang diambil sebagai terdiaganosa gejala itu memiliki penyakit baru, maka dari hasil pengukuran tersubut metode certaity factor dapat diimplementasikan pada sistem pakar diagnosa penyakit tanaman bawang merah. dari hasi analisa menggunakan 35 data terdapat 5 data yang nilai yang sama, maka dari hasil yang sama dilakukan pengujian menggunakan metode tanimoto distance hasil 0, 0,75, 1, semakin nilainya mendekati nol maka semakin banyak jumlah total kategori yang berhasil dipredeksi secara benar. Dari hasil berdasarkan pengujian sistem, dengan melakukan perbandingan hasil diagnosa pakar dan hasil diagnosa sistem diperoleh akurasi $85,71 \%$. Penelitian selanjutnya dapat mengembangkan sistem pakar diagnosa penyakit tanaman bawang merah dengan menambah diagnosa penyakit yang lebih lengkap, diharapakan mennggunakan metode-metode baru yang lebih baik tingkat efisiensi dan akurasinya. Sistem pakar yang dikembangkan disarankan dapat dirancang di platform lainnya, seperti mobile sehingga penerapannya akan menjadi lebih luas dan bisa digunakan oleh setiap orang.

\section{UCAPAN TERIMA KASIH}


Ucapan terima kasih diperuntukan bagi Universitas Muhammadiyah Jember dan semua pihak yang telah membantu untuk menyelesaikan penelitian ini.

\section{REFERENSI}

[1] L. Baswarsiati, B. Rosmahani and R. Nusantoro, "Pengkajian Paket Teknik Budidaya Bawang Merah di Luar Musim," in Prosiding Seminar Hasil Penelitian dan / Pengkarjian BPTP Karang Ploso, 1997.

[2] S. Kusumadewi, Atificial Intelegence (Teknik dan Aplikasinya), Yogyakarta: Graha Ilmu, 2003.

[3] S. Halim and S. Hansun, "Penerapan Metode Certainty Factor dalam Sistem Pakar Pendeteksi Resiko Osteoporosis dan Osteoarthritis," Ultima Computing : Jurnal Sistem Komputer, vol. 7, pp. 59-69, 2016.

[4] K. E. Setyaputri, A. Fadlil and S. , "Analisis Metode Certainty Factor pada Sistem Pakar Diagnosa Penyakit THT," Jurnal Teknik Elektro, vol. 10, no. 1, 2018.

[5] R. Hariyanto and K. Sa'diyah, "Sistem Pakar Diagnosis Penyakit dan Hama Pada Tanaman Tebu Menggunakan Metode Certainty Factor," (JOINTECS) Journal of Information Technology and Computer Science, vol. 3, no. $1,2018$.

[6] A. H. Permana, R. A. Asmara and R. T. Ariadi, "Sistem Pakar Diagnosa Hama Dan Penyakit Pada Tanaman Apel Menggunakan Metode Certainty Factor," JIP, vol. 1, no. 3, 2017.

[7] Y. Desnelita, K. Rukun and Syahril, "Intelligent Decision Support System Using Certainty Factor Method For Selection Student Carrer," in International Conference on Electrical Engineering and Informatics (ICon EEI 2018), Batam, 2016.

[8] S. F. Rodiyansyah and E. Winarko, Klasifikasi Posting Twitter Kemacetan Lalu Lintas Bandung Menggunakan Naive Bayes Classification, Yogyakarta, 2013.

[9] S. Putrasamedja and Suwandi, Varieatas Bawang Merah, Lembang Banding, 1996. 